\title{
Concept of teaching discipline Chemistry of an Environment
}

\author{
Marina D. Vedenyapina ${ }^{1,2, *}$ and Albert A. Vedenyapin ${ }^{1.2}$ \\ ${ }^{1}$ Moscow Technological Institute, 199334, Moscow, Russia \\ ${ }^{2}$ Zelinsky Institute of RAS, 119991 Moscow, Russia
}

\begin{abstract}
The educational space in a modern society is sharply expanded in comparison with the last centuries. Objectively occurs globalization in sphere of education. In this connection has ripened necessity more or less precise definition of frameworks of educational space at teaching discipline « Chemistry of an environment ». First of all, it is necessary to emphasize, that this discipline should give understanding about chemical compounds of all making natural the environments and about chemical reactions which proceed or can proceed in the ore.
\end{abstract}

\section{Introduction}

The educational space in a modern society is sharply expanded in comparison with the last centuries where knowledge were transferred from the teacher to the pupil. If 50 more years back the slogan "the book - the source of knowledge" really reflected the basic way of knowledge now pupils have a wide choice of sources of knowledge, educational institutions and even is concrete the teacher. It is caused basically by that the world has come in information epoch - in epoch of general consumption of the wide information on all spheres of human activity and on all sides of real life. Objectively occurs globalization in sphere of education. It imposes on teaching of any disciplines the requirement, even in the most rudimentary kind, unification of concepts and standardization of definitions.

\section{Analysis and discussion}

In this connection has ripened necessity more or less precise definition of frameworks of educational space at teaching discipline " Chemistry of an environment ». Now this discipline has no practically the educational niche. It is enough to take practically any textbook in this subject to be sure, that in it of concepts Chemistry of an environment it is not separated from concepts "ecological chemistry", "environment protection" and even simply «ecology» [1]. Though the last term initially designated only the certain section of biology. Also put is and in the English-speaking literature where the situation is aggravated with that in English environment chemistry and ecological chemistry essence one and too.

Unfortunately, textbooks at the course Chemistry of an environment a little than differ from textbooks at the course "environment protection" considering chemical substances in a nature basically as anthropogenous pollutants. Moreover even developers competences have not avoided this temptation to transform chemical problems to problems of environment protection. So by us it was earlier specified [2,3], the personal competence $\mathrm{PC}-1$ brought in the working program, unfortunately, has no any relation to discipline Chemistry of an environment and has got in WP as obligatory only because the developer of this competence suppose, that concepts chemistry of an environment and "protection of an environment" are the same.

In a Chemistry of an environment clearly first of all it is necessary to show, that all natural environmental are chemical compounds and life among and inside these natural objects demands knowledge of chemistry.

It would be possible to point out a framework of an educational field on discipline Chemistry of an environment some show of array of educational directions which set is especially specific to this discipline.

First of all, it is necessary to emphasize, that this discipline should give understanding about chemical compounds of all making natural the environments and about chemical reactions which proceed or can proceed in the ore.

The place of discipline Chemistry of an environment among other disciplines is defined by that the knowledge received here are necessary at studying such subjects, as "Ecology", "Industrial ecology", "Economy of natural resources", "Improvement solid", "Meteorology", "Global change of a climate", etc.

Knowledge received at it are necessary the pupil and for maintenance of erudition of the modern person living in the world in which the natural environment is object of constant attention as on state, and a world level. Representations about chemical substances in a nature are actual and in daily life - for example, at consumption of natural mineral waters, at use of the cosmetic and medical preparations containing natural components, at

* Corresponding author: mvedenyapina@yandex.ru 
work on a country site, at a choice of a place of realization of holiday etc.

Within the framework of discipline Chemistry of an environment it is necessary to consider also problems of global use of the natural resource resulting global change of a concentration of chemical compound of geospheres of the Earth (extraction of metal ores, pumping out of petroleum and gas, extraction of fracking gas and coal etc.). However in this case it is not necessary to suppose transformation of this question, after politics, in a political question. It is necessary to remember, that hypotheses about "greenhouse effect" or $\mathrm{O}_{3}$ - destroying by chlorine organic compounds are only hypotheses and should not be considered as serious fundamental scientific conclusions.

Some questions, for example, mentioned below, in programs and textbooks in Chemistry of an Environment are usually are discussed poorly or not mentioned at all.

-Ways of a deposition of $\mathrm{CO}_{2}$ out atmosphere. Here the special attention is necessary to give a role of biosphere in deposition $\mathrm{CO}_{2}$ [4].

-Sources of enrichment of an atmosphere by methane and ways of its deposition with consideration of a role of alive organisms.

-Inert gases in geospheres of the Earth

-The detailed description of structure and ways of a mineralization of natural waters.

-Chemical compound and chemical reactions in solid.

-Geochemical barriers.

-Chemical reactions in an atmosphere proceeding under influence of solar radiation and electric discharge.

-Chemical compound and the basic natural reactions in ores.

-Accumulation of energy in natural chemical compounds etc. [5].

The specified frameworks of an educational field on discipline Chemistry of an environment bring than the requirement and to competences, which the pupil should seize is more certain. So the personal competence PC-16 according to it should be directed on skill to be guided in a condition of the natural environment and change of it first of all under influence of natural factors at use of modern engineering of the control of parameters of an environment. The competence here an equivalent to concepts "to know and be able" and quite can be supervised by a method of tests. As the competence PC16 has no precise professional orientation and connection with discipline development the general recommendation here should be detailed by the teacher according to a structure of training.

\section{Conclusions}

Teaching discipline Chemistry of an environment demands from the teacher of wide erudition as there is no such branch of a science as «chemistry of an environment», and for drawing up of a course of lectures and seminars It is necessary the complex approach with inclusion in the program of required sections from "analytical chemistry", "geochemistry", "chemistry of an atmosphere", "hydrogeology", "gas-chemistry" etc.

The teacher can and should work own flexible system of inclusion of elements of vocational training in lectures and seminars so that the taught rate had individual character.

\section{References}

1. I.F. Goldovskay, Chemistry of Environments (WORLD, 2005)

2. M.D. Vedenjapina, A.A. Vedenjapin., Differencale studying of sciences about a nature and interaction with it of the person. In Proceedings of VIII International conference Educational environment today and tomorrow, p. 56-57 (MTI, 2013)

3. M.D. Vedenjapina, A.A. Vedenjapin, The analysis professional competences on discipline Chemistry of an environment. In Proceedings of IX International conference educational environment today and tomorrow, p. 30-32 (Moscow, 2014)

4. M.D. Vedenjapina, J.A. Strizhakova., A.A. Vedenjapin, A.L. Lapidus. Ecology of the industry of Russia, 10, 1-4 (2008)

5. A.I. Perel'man. Geochemistry of biosphere (Science, 1973) 